\title{
Student Self-Efficacy and Gender-Personality Interactions
}

\author{
Lars Fallan ${ }^{1} \&$ Leiv Opstad ${ }^{1}$ \\ ${ }^{1}$ Trondheim Business School, Norwegian University of Science and Technology (NTNU), Trondheim, Norway. \\ Correspondence: Lars Fallan, Trondheim Business School, NTNU, c/o Stiftelsen Den Nordenfjeldske \\ Handelshøyskole, Sluppenveien 23A, 7037 Trondheim, Norway. E-mail: lars.fallan@ntnu.no
}

Received: May 9, 2016

Accepted: May 20, 2016

Online Published: May 30, 2016

doi:10.5430/ijhe.v5n3p32

URL: http://dx.doi.org/10.5430/ijhe.v5n3p32

\begin{abstract}
The present study examines the self-efficacy levels and self-efficacy strength for male and female students in a course in Principle of Economics. The groups of male and female students may be mutually heterogeneous when it comes to personality types in a business school (Fallan \& Opstad, 2014). This study does not treat the gender groups as internally homogeneous and examines how gender and gender-personality interactions separately affect self-efficacy. The participants are students enrolled at Trondheim Business School, Norwegian University of Science and Technology. These students have answered a questionnaires based on Meyer-Briggs Type Indicator (MBTI) and questions about their perceived self-efficacy in Principles of Economics.

The study reveals that female students have significantly lower self-efficacy level and self-efficacy strength than their male peers. However, this general conclusion does not hold for all gender-personality types. Lower self-efficacy level in economics for female students compared to those of their male peers does only exist for female intuition and feeling $(N F)$ and intuition and thinking students $(N T)$, not for the female sensing and perceiving student $(S P)$. Furthermore, higher self-efficacy level for male students does only exist for male intuition and thinking students $(N T)$ and not for male $N F$ and $S P$ students.

Female students have significantly lower self-efficacy strength than their male peers as well. However, this does only exist for female intuition and thinking $(N T)$ and sensing and perceiving $(S P)$ students, but not for female $N F$ students. The general result that male students have significantly higher self-efficacy strength than their female peers does only encompass male intuition and thinking (NT) students and not the male $S P$ and $N F$ students.

The main contributions of this study are showing the need to go beyond gender to get a more complete picture of the differences in self-efficacy between female and male students. We should be cautions to conclude that self-efficacy is uniformly affected by gender. Gender-personality interactions do matter.
\end{abstract}

Keywords: Self-efficacy, Gender differences, Gender-personality interactions, Economics

\section{Introduction}

\subsection{The Problem of Gender Differences of Perceived Self-efficacy}

Knowledge, transformational operations, and constituent skills are necessary but insufficient for accomplishing performance. Self-referent thought is an important part of psychological theories that mediates relationship between knowledge and action. According to social learning theory (Bandura, 1986, 1997) a student's perceived self-efficacy has turned out to be a significant determinant of performance that operates partially and independently of underlying skills (e.g. Locke et al., 1984; Schunk, 1984a, 1984b; Peters, 2012; Gegenfurtner et al., 2013). A meta-analysis of self-efficacy and work-related performance is clearly answered (Stajkovic \& Luthans, 1998). However, sources of discordance between self-efficacy belief and action are put forward in some studies (e.g. Vancouver \& Kendall, 2006; Yeo \& Neal, 2006; Judge et al., 2007). These objections are explored and discussed by Bandura (2012) where functional properties of perceived self-efficacy revisited are highlighted. Still, exploring a student's self-efficacy is important for a better understanding of how to improve quality in higher education.

Economists contribute to the current debate on quality in higher education by applying the educational production function, where academic achievement is a function of student capability, time devoted to learning, various attributes and attendance in an experimental treatment (e.g. Schmidt, 1983). Gender is often one of these attributes included in the educational production function. 
There are several studies indicating that males perform better in college economics than females (Siegfried, 1979; Ferber et al., 1983; Lumsden \& Scott, 1987; Gohman \& Specter, 1989; Watts \& Lynch, 1989; Williams et al., 1992; Anderson et al., 1994; Opstad \& Fallan, 2010). However, these results are not universal. Some studies have found no significant gender effect on student performance in economics when course grade is a dependent variable (Kelley, 1975; Buckles \& Freeman, 1983; Watts, 1987; Rhine, 1989; Borg \& Shapiro, 1996; Parker, 2006; Swope \& Schmitt, 2006).

These diverging findings may be due to the fact that gender groups are mutually heterogeneous when it comes to personality types of students in a business school. Self-efficacy of female and male students may probably be affected by what personality types the students belong to. It is too simple to presuppose that each group consist of homogenous personality distribution and thereby the same self-efficacy orientation. Self-efficacy significantly affects academic performance and, hence, the gender-personality orientation may reveal an important relation to self-efficacy and to academic performance.

An essential part of assessing the outcome of different learning processes is the influence of the personality of the student involved. Hence, a student's personality type should be included to reveal how self-efficacy is affected as well. However, previous studies examining the effect of personality type on a student's performance in Principles of Economics (Borg \& Shapiro, 1996; Ziegert, 2000) did not find significant gender effect on performance when personality types were included in the model. The missing gender effect on performance in the Borg and Shapiro study (1996) may be due to personality differences between men and women. If this is so, gender effects will disappear when personality types are controlled for. Borg and Shapiro (1996) hypothesized that this might be the case, but they did not test the hypothesis. In this study we shall explore how self-efficacy is affected by gender - personality interaction.

This article is organised as follows: We elaborate on a literature review, the importance of perceived self-efficacy for academic achievement, and clarifies the distinctions of preferences behind personality types based on the Briggs-Meyer Type Indicator (MBTI). Thereafter, we elaborate on how to explore self-efficacy and gender-temperament interaction. Data and research methodology underlying the empirical study are explained. Thereafter the findings are reported, conclusions are drawn and, finally, some implications and limitations are indicated.

\subsection{Review of Literature}

Two studies have tested the significance of the interaction of gender and personality type on performance in Principles of Economics. First, Borg and Stranahan (2002a) have re-examined the study by Borg and Shapiro (1996) which includes a sample of 119 college students enrolled in a class of Principles of Economics at the University of North Florida (UNF) to test the interaction of gender and personality type on performance. Second, Opstad and Fallan (2010) have studied the same interaction among 296 students in classes of Principles of Economics at Trondheim Business School (TBS). Both studies examined the effect of gender in conjunction with personality type on the student's performance and concluded that gender does matter in a student's performance in Principles of Economics. However, the relation has not turned out to be in a simple, direct way as some previous studies had revealed. They found that gender combined with personality type form more subtle, interactive effects on a student's probability of success in economics. Not all female personality types performed poorer than males, and not all male personality types performed better than their female peers.

Self-efficacy was no part of these two studies. However, it is well known that an individual's belief that he or she can master a specific task or topic is positively related to the probability of succeeding. For example, any teacher knows that if a student does not believe that he or she can master a specific challenge, it is difficult for the student to succeed. Thus an important part of the teacher's task is to develop and support the student's self-confidence. Self-efficacy is a very similar notion and relates to the strength of individuals' belief in their own capability to cope with a particular task (Bandura, 1986, 1997, 2012). It has also been found that people with a high degree of self-efficacy tend to engage more frequently in task-related activities and persist longer in coping with efforts than people with a low self-efficacy (Gist, 1987).

Adopting the four personality temperaments developed by Keirsey and Bates (1984), based on the MBTI, and making them interact with gender, we are able to explore differences in self-efficacy. These four mutually exclusive combinations are sensing and perceiving $(S P)$, sensing and judging $(S J)$, intuition and thinking $(N T)$, and intuition and feeling $(N F)$. These categories are briefly elaborated in a subsequent section.

This study explores how these gender/temperament combinations affect a student's self-efficacy in Principles of Economics. Unlike the study by Borg and Stranahan (2002a) Opstad and Fallan (2010) have revealed performance 
differences between female and male students even if personality types are included in the model. However, both these studies have revealed differences within each group of female and male students as to what temperament they belong to. Therefore, the aim of this study is to explore the patterns of self-efficacy in Principles of Economics in this gender-temperament perspective. A better understanding of how self-efficacy in economics relates to student's gender and personality type will help to fine-tune the teacher's effort to develop and support the students' self-efficacy and thereby their performance.

\subsection{Perceived Self-efficacy and Academic Achievement}

Perceived self-efficacy is defined as how individuals judge their own capability to organize and execute courses of action required to attain designated types of performance (Bandura, 1986). Bandura (1997) hypothesized that mastery experience is the most powerful source of self-efficacy. And according to Usher and Pajares (2008) mastery expectations emerge to be a significant source in empirical studies of self-efficacy. Fallan and Opstad (2003) have included self-efficacy based on mastery and output expectations as an independent variable in the educational production function of academic achievement in Principles of Economics. They found a strong and significant effect of self-efficacy on academic achievement in economics.

The theory of self-efficacy states that «it is concerned not with the skills one has but with judgements of what one can do with whatever skills one possesses» (Bandura, 1986, p. 391). Therefore, there is no simple equivalence of performance to perceived capability. Many factors can affect level of performance that may have little to do with skills or capability. Self-efficacy is one of these. Hence, providing better understanding of how self-efficacy is related to the interactions between gender and personality type is important knowledge for the teacher's task to enhance self-efficacy and thereby improve student performance.

\subsection{Personality and Temperament Type}

As far as we know there is no study of how gender and personality types affect self-efficacy in Principles of Economics. However, there is a voluminous amount of research into how personality types affect the learning in general. Studies of personality and temperament type are using the MBTI or The Big Five Personality Dimensions (Barrick \& Mount, 1991) to evaluate the effect of personality types on educational outcomes. This study adopts MBTI because TBS has collected such data from students for several years to assess appropriate learning style and how student personality type affects preferred selection of majors (Fallan, 2006). MBTI uses a person's preferences rather than a clinical diagnosis to indicate personality type (Benfari \& Knox, 1991).

MBTI reveals a person's preferences. In this study we limit the focus to three dimensions: sensing (S) versus intuition $(\mathrm{N})$, thinking $(\mathrm{T})$ versus feeling $(\mathrm{F})$, and judgement $(\mathrm{J})$ versus perception $(\mathrm{P})$.

The mental process of sensing versus intuition refers to a person's preferred way of acquiring information about the world. No one uses only one of these mental processes alone, but one of them is more fully developed. Hence, according to the MBTI a person reveals to be either sensing $(\mathrm{S})$ or intuitive $(\mathrm{N})$. This is based on which of the two mental processes that is the most developed by the person.

The mental process that determines how people prefer to make judgements judges information in one of two ways: thinking or feeling. Although every person may use both these ways of making judgments, only one of them will dominate. Thinkers ( $\mathrm{T}$ ) use the thinking process more often and it becomes more fully developed. The opposite is true for feeling persons $(\mathrm{F})$.

Myers and Briggs expanded on these original personality types by adding another dimension to the MBTI to clarify which is a person's dominant function. An 'orientation' variable is introduced to indicate which kind of function judging $(\mathrm{J})$ or perceiving $(\mathrm{P})$ - a person mostly used in dealing with the outer world.

These dimensions are measured through a series of items in the MBTI. The individual is asked to decide between dichotomous choices of phrases designed to reveal his or her preferences in these mental processes. The series of items will induce the individual to reveal mental processes, whether we have a thinking $(\mathrm{T})$ or a feeling $(\mathrm{F})$ person's judging process, and whether we have a sensing $(\mathrm{S})$ or intuitive $(\mathrm{N})$ person's perceiving process. Likewise, judgement $(\mathrm{J})$ cannot be matched with perception (P). According to the MBTI these mental processes in pairs are seen as polarities. 
Table 1. Polarities Describing a Person's Personality Type

\section{S: Sensing}

The person prefers to perceive the immediate, real, practical facts of experience and life.

\section{N: Intuition}

The person prefers to perceive the possibilities, relationships, and meanings of experiences.

\section{T: Thinking}

The person prefers to make judgments and decisions objectively, impersonally, considering causes of events and where decisions may lead.

\section{F: Feeling}

The person prefers to make judgments and decisions subjectively and personally, weighing values of choices and how they matter to others.

\section{J: Judgment}

The person prefers mostly to live in a decisive, planned, and orderly way, aiming to regulate and control events.

\section{P: Perception}

The person prefers mostly to live in a spontaneous, flexible way, aiming to understand life and adapt to it.

Source: Lawrence (1993).

No study has explored the relationship between self-efficacy and the combination of gender and personality temperaments in the subject of economics. However, there are studies on how personality types and learning styles affect performance in economics (Borg \& Shapiro, 1996; Ziegert, 2000; Borg \& Stranahan, 2002a, 2002b) and have adopted four temperaments based on the MBTI from Keirsey and Bates (1984). So did Fallan (2006) who studied the relationship between personality temperaments and preferred learning style and self-selected majors in a business school. Hence, the same four temperaments are adopted in this study. These four temperaments include a combination of two of the four Myers-Briggs categories. These four mutually exclusive combinations are sensing and perceiving $(S P)$, sensing and judging $(S J)$, intuition and thinking $(N T)$, and intuition and feeling $(N F)$.

The $S P$ student prefers physical involvement in the learning process and want to try things themselves. They tend to be competitive and do often respond well to group projects, particularly if the groups are involved in some sort of contest, such as a stock market game. These students require a great deal of variety in the learning process, and will be bored by a standard class lecture and traditional paperwork such as workbooks and end-of-the-chapter questions (Lawrence, 1993).

The $S J$ student prefers the traditional learning style with a lecture-based classroom. They prefer structure in their learning environment and a sequential presentation of the material in increments that make sense to them. $S J$ 's prefer to have paper topics assigned to them rather than having to choose their own. They may become uncomfortable in classroom discussions. These students prefer to study facts and procedures and may dislike assignments which require improvisation and creativity.

The $N T$ student tends to be an independent learner and is often self-sufficient in the classroom. They prefer to choose their own paper topics and would even like to have some control over the subject matter of the course. NT's prefer theoretical, logical and didactical presentation and need few examples to follow up a theoretical presentation. They may become impatient in the classroom. NT's prefer to have discussions with the professor rather than with other students, and they do not interact well in group discussions or group assignments.

The $N F$ student prefers a democratically run classroom where there is much interaction with other students and with the professor. They enjoy group work being cooperative rather than being competitive. $N F$ 's tend to be sensitive to hostility and conflict and, hence, they will dislike very competitive environments. These students learn best through class discussions and case studies. They do better in classes that require papers and essays rather than more objective means of evaluation. $N F$ students are motivated by personal recognition and approval on papers or tests rather than good grades. 


\section{Data and Methodology}

\subsection{Sample}

The sample includes students in Principles of Economics being enrolled in classes at TBS. The sample was not chosen at random. In fact the sample comprised students in these compulsory classes in the autumn semester of their second year at TBS. No optional subjects were offered in the first year of their business educations. Hence, these students had taken the same compulsory subjects and, therefore, should have had almost identical background knowledge of business subjects.

The personality test was conducted during the last lecture of the compulsory course of Principles of Economics in the autumn term of the second academic year. The students answered questionnaires based on MBTI to reveal which of the non-equivalent personality temperament groups they belong to. The participation was on a voluntary basis. The students answered more questions, e.g. about their effort in the subject measured as out of class study time during the term, and they were asked to reveal their self-efficacy in economics. However, the first years of our collection of data self-efficacy was only measured by strength. Later on we started to add a measure of the level of self-efficacy among the students. Hence, the sample of self-efficacy measured only by level includes fewer students than the sample of students measured by both level and strength. The first sample includes 405 students and the second sample has 798 students.

These samples contain only those students (1) who participated in the last class before the final exam and (2) who voluntarily answered the questionnaire. Most students attended the last classes and very few of them refused to participate in the study. However, since the sample only contains students who participated in the last class, this could cause a slight upward bias in self-efficacy. Like Borg and Stranahan (2002a) we believe that drop-outs primarily include students who are doing very poorly in the course and, hence, have low self-efficacy. However, this is a compulsory course, and students cannot easily drop out because then they fail to obtain their bachelor degree in Business Administration.

The same professor was teaching these classes. The courses had identical curriculum and the exam questions were differently made though having the same degree of challenge for the students each year.

\subsection{Dependent Variable: Self-efficacy}

Self-efficacy is a critical success factor in the learning process and relates to the strength of individual people's belief in their own capability to cope with a particular task. In this case self-efficacy is connected with the student's perceived judgements of how well he or she is able to perform in Principles of Economics.

The concept of self-efficacy has received increasing attention in empirical research, but there is no generally agreed way of measuring the concept (Gist \& Mitchell, 1992; Usher \& Pajares, 2008). Zimmerman (2000) points out that before Bandura introduced self-efficacy as an important concept in social cognitive theory, he discussed human motivation primarily in terms of outcome expectations. Bandura (1997) defined perceived self-efficacy as personal judgements of one's capabilities to organize and execute courses of action to attain designated goals, and he included assessment of its level, generality, and strength. The level of self-efficacy refers to its dependence on the difficulty of a particular task, generality pertains to the transferability of self-efficacy beliefs across activities, and strength of self-efficacy is measured by the amount of one's certainty about performing a specific task successfully.

Owen (1986) claims that the concept is easily measured, and that it gives a complex image of affect, cognition and achievement. Lee and Bobko (1994) concluded that the best measurements are achieved by specifying several skills or activities within a defined area and asking the respondents two questions for each activity: (1) are you capable of carrying out the activity ("yes" or "no"), i.e. self-efficacy level or difficulty dimension, and (2) if "yes", to what degree are you confident that you can execute the task, i.e. self-efficacy strength.

However, perceived academic self-efficacy is organized hierarchically, which means that the student belief develops over time from start to end of the course (Galyon et al., 2012). At the end of a course in economics students are able to express their belief of the broad domain of skills required in the subject. In this study the students have answered the questionnaire at the end of the course but before the final exam. Then, we may drop to ask the students of their beliefs of how well they can execute separate skills, but ask them of their beliefs regarding their capabilities in the academic domain of economics (Lent et al., 1997).

We have decided to measure two dimensions of Banduras self-efficacy concept: the level and the strength of self-efficacy. Level is measured by asking the student how difficult he or she experienced Principles of Economics to 
be. The answer is measured at a five-point Likert scale ranging from very high (1) to not at all (5). High score is an indication of high self-efficacy level.

Strength is the degree of confidence that the student is capable of solving tasks in Principles of Economics successfully. The student was asked what he or she expected their final grade to be. The student's expected final grade is adopted as a proxy for self-efficacy strength. The grade system in Norway range from Fail $(F)=0$ to Outstanding $(A)=5$. High score in the final exam is an indication of high self-efficacy strength.

\subsection{Independent Variables}

We have adopted independent variables from the educational production function, i.e. student capability, effort, gender and personality temperament to study how self-efficacy is affected.

The proxy for the general capability of a student is the grade point average (GPA) from high school. In the Norwegian school system we have nothing like «Student Admittance Test» (SAT). GPA is the competing factor in business schools having restricted admission. According to Keirsey and Bates (1984) SJ students do very well in a traditional school setting, e.g. in high schools. Hence, it is no surprise that Fallan (2006) found that $S J$ students were the majority group among students in a Norwegian business school having restricted admission.

Student effort devoted to learning has been interpreted in different ways and with mixed results in the educational production function (Parker, 2006). Some studies use attendance at lectures as a proxy for student effort (Romer, 1993; Durden and Ellis, 1995; Stratford and Sulock, 1995; Marburger, 2001). Other studies measure effort as out of class study time (Leppel, 1984; Borg et al., 1989; Park and Kerr, 1990). However, study time does not say anything about the productivity of the time devoted to these activities. We adopt out of class study time as a proxy for student effort in the present study. We ask the student how many hours on average per week he or she is working with this specific subject when lectures are excluded.

The main purpose of this study is to explore how gender and the temperaments of Keirsey and Bates (1984) are affecting self-efficacy. The measurement of gender is Female $=0$ and Men $=1$. MBTI $=$ dummy variables indicating temperament type. These interactions are measured by variables indicating the interaction of gender and temperament type, e.g. Female $\mathrm{NF}=1$ and 0 if not.

Table 2. Measurement of variables. Descriptive statistics: Mean (Standard Deviation), and $T$-test gender difference. Per cent males in gender category and per cent interactions.

\begin{tabular}{|c|c|c|c|c|c|}
\hline Variables & Measurement & $\begin{array}{l}\text { Entire sample } \\
\text { mean (SD) }\end{array}$ & $\begin{array}{l}\text { Female mean } \\
\text { (SD) }\end{array}$ & $\begin{array}{l}\text { Male mean } \\
\text { (SD) }\end{array}$ & $\begin{array}{l}T \text {-test gender } \\
\text { difference }\end{array}$ \\
\hline $\begin{array}{l}\text { Self-efficacy } \\
\text { level }\end{array}$ & $\begin{array}{l}\text { Difficulty: } 1=\text { very } \\
\text { high, } 2=\text { high, } 3=\text { low, } \\
4=\text { very low, } 5=\text { not at } \\
\text { all }\end{array}$ & $2.19(.88)$ & $2.01(.82)$ & $2.47(.86)$ & $-6.94^{* * *}$ \\
\hline $\begin{array}{l}\text { Self-efficacy } \\
\text { strength }\end{array}$ & $\begin{array}{l}\text { Expected final grade: } F \\
=0, E=1, D=2, C=3, \\
B=4, A=5\end{array}$ & $3.47(.75)$ & $3.32(.73)$ & $3.66(.72)$ & $-7.59^{* * * *}$ \\
\hline Capability & $\begin{array}{l}\text { Grades } \\
\text { outstanding to fail: } 6,5, \\
4, \quad 3, \quad 2, \quad 1 . \text { GPA } \\
\text { multiplied by } 10 \text { plus } \\
\text { additional points }\end{array}$ & $52.42(3.92)$ & $52.47(4.04)$ & $52.32(3.72)$ & .59 \\
\hline Effort & $\begin{array}{l}\text { Working hour on } \\
\text { average per week } \\
\text { lectures excluded }\end{array}$ & $3.41(2.42)$ & $3.53(2.36)$ & $3.19(2.50)$ & $2.38^{*}$ \\
\hline Gender & Female $=0$, Male $=1$ & $.45(.50)$ & & & \\
\hline SJ & $\mathrm{SJ}=1$ Otherwise $=0$ & $.67(.47)$ & $.71(.46)$ & $.62(.49)$ & $3.03^{* *}$ \\
\hline SP & $\mathrm{SP}=1$ Otherwise $=0$ & $.12(.32)$ & $.10(.30)$ & $.15(.35)$ & $-2.41^{*}$ \\
\hline NT & $\mathrm{NT}=1$ Otherwise $=0$ & $.17(.38)$ & $.14(.35)$ & $.21(.41)$ & $-2.99^{* *}$ \\
\hline NF & $\mathrm{NF}=1$ Otherwise $=0$ & $.04(.21)$ & $.06(.24)$ & $.03(.17)$ & $2.22^{*}$ \\
\hline
\end{tabular}

Significance level (two-tailed) ${ }^{*} \mathrm{p}<.05 ;{ }^{* *} \mathrm{p}<.01 ;{ }^{* * * *} \mathrm{p}<.001$ 
Table 2 includes measurement, descriptive statistics and $T$-test of gender differences. The self-efficacy - both level $(t=$ $-6.94, \mathrm{p}<.001)$ and strength $(t=-7.59, \mathrm{p}<.001)$ - reveals significant differences between female and male students. Male students have significantly higher self-efficacy. On the other hand there are no capability differences between female and male students when it comes to GPA as admittance indicator to the business school. However, there are significant differences on out of class effort between female and male students $(t=2.38, \mathrm{p}<.05)$. Female students are working on average 3.53 hours ( $\mathrm{SD}=2.36$ ) out of class per week while male peers are working 3.19 hours $(\mathrm{SD}=2.50)$.

There are fewer male students than female peers in the sample. Male students constitute 45 per cent of the sample. The $S J$ students are the largest temperament group including 67 per cent of the students in the business school. There are significantly more female $S J$ 's than males $(t=3.03, \mathrm{p}<.01)$. The second largest personality group is $N T$ students including 17 per cent of the business students. Unlike the previous group there are significantly more male than female NT students $(t=-2.99, \mathrm{p}<.01)$. There are 12 per cent $S P$ students in the sample, and the males constitute a significant majority in this temperament group too $(t=-2.41, \mathrm{p}<.05)$. There are fewest $N F$ students in the sample, only 4 per cent. Even if this group is small, it has significantly more females than males $(t=2.22, \mathrm{p}<.05)$.

\subsection{Empirical Models}

The dependent variable is self-efficacy. However, we have not combined the assessment of level and strength, but these two dimensions of the self-efficacy concept is explored separately in Model 1 (level) and 2 (strength) respectively. Each model has two different sets of independent variables: (a) no gender interaction, and (b) gender interaction included. In the models below, $\alpha$ is a constant, $\varepsilon$ is stochastic error, and the betas $(\beta)$ are standardised regression coefficients.

The student's temperament type described by Kersey and Bates (1984) is one of the four mutually exclusive combinations $S P, S J, N T$, and $N F$. These are dummy variables. However, one of them has to be omitted in order to avoid multicollinearity. We have omitted SJ. These students have the greatest success in economics (Opstad \& Fallan, 2010).

The first model tests how gender affects self-efficacy - level (1a) and strength (2a) - when personality temperaments are controlled for. Each temperament group consists of both female and male students in this model, and, hence, gender - temperament interaction is not tested here.

Model 1 (a) and 2 (a):

SELF-EFFICACY $=\alpha+\beta_{1}$ CAPABILITY $+\beta_{2}$ EFFORT $+\beta_{3}$ GENDER $+\beta_{4} \mathrm{NF}+\beta_{5} \mathrm{NT}+\beta_{6} \mathrm{SP}+\varepsilon$

The second model tests how gender - temperament interaction affects self-efficacy level (1b) and strength (2b). The gender variable above, which includes all female and male students independent of their personality temperament, is excluded and replaced by gender - temperament interactions. Not all female and male students within their specific group may perceive self-efficacy the same way. Hence, the model below explores whether the gender - self-efficacy relation is affected by gender - temperament interaction.

Model 1 (b) and 2 (b):

SELF-EFFICACY $=\alpha+\beta_{1}$ CAPABILITY $+\beta_{2}$ EFFORT $+\beta_{3}$ FemaleNF $+\beta_{4}$ FemaleNT $+\beta_{5}$ FemaleSP $+\beta_{6}$ MaleNF $+\beta_{7}$ MaleNT $+\beta_{8}$ MaleSP $+\varepsilon$

Both models isolate the effects on self-efficacy from the interaction of gender and personality temperament by controlling for capability and effort.

\section{Results}

The results from the regression analyses estimated with a maximum likelihood estimation technique are presented in Table 3. The table shows the standardized beta coefficients, $t$-values, and significance level.

Previous research (e.g. Opstad \& Fallan, 2010) results provide a priori expectations about some of the signs of the predicted coefficients, but not for all. These signs in parentheses indicate the expected direction of the relationship to self-efficacy: gender (+), capability (+), effort (+), MBTI (?), interactions for female temperament (?), interactions for male temperament (?). Therefore we decided to conduct a two-tailed test of significance, with a null hypothesis of no predicted relationship between the student input variables and self-efficacy.

\subsection{Model 1 (a) Self-efficacy Level, Gender Interaction Excluded}

Table 3 reveals that male students perceive self-efficacy level to be significantly higher than their female peers ( $\beta=.29$, $\mathrm{p}<.001)$. This means that female students perceive economics to be significantly more difficult than the male students. Since the $N F, N T$ or $S P$ temperaments include both female and male students the gender heterogeneity within each 
temperament group may dilute the effect on self-efficacy level. Neither of these temperaments significantly affects self-efficacy level.

Table 3. Multiple regression analyses (OLS). SJ, female SJ og male SJ are omitted from the models.

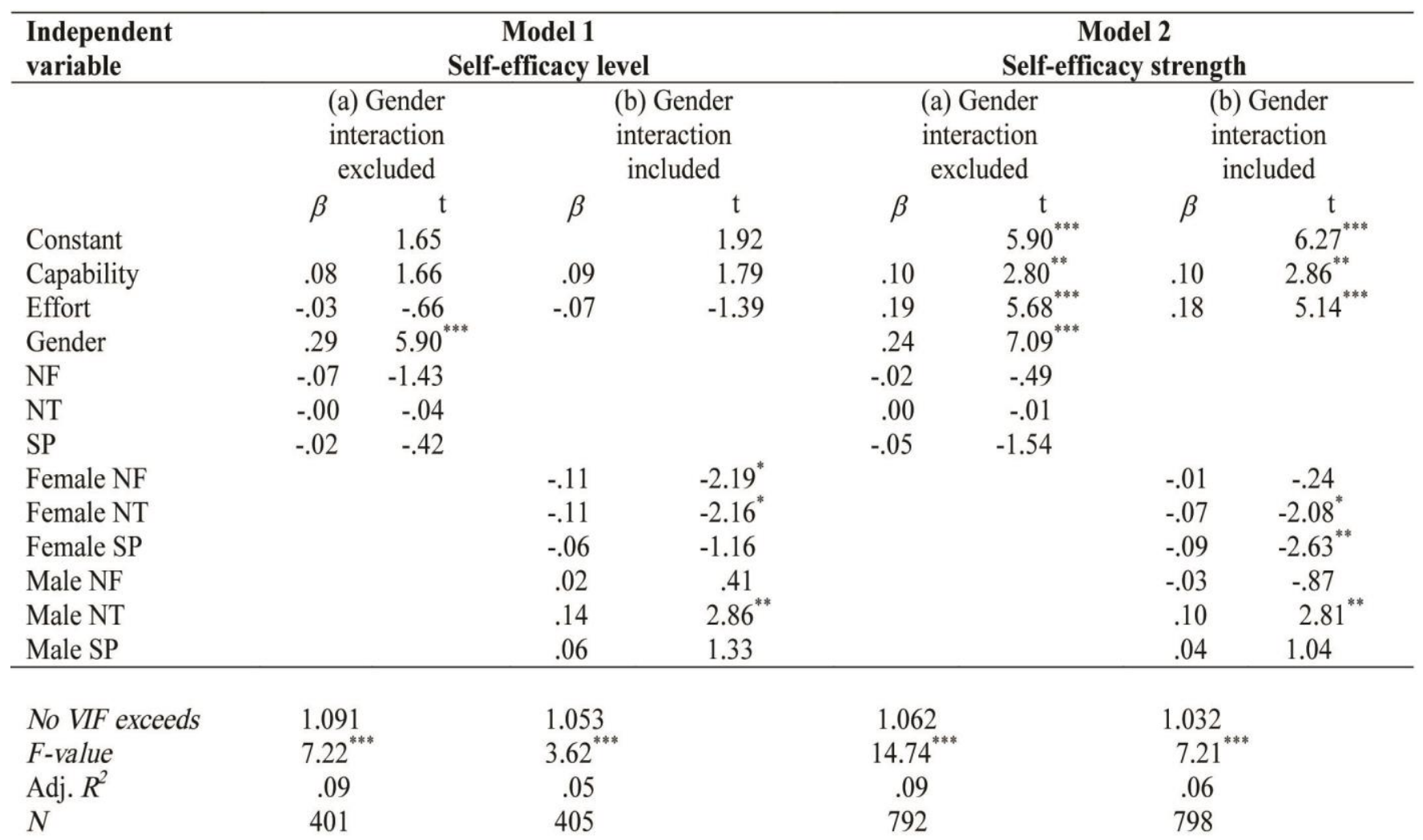

Significance level (two-tailed): ${ }^{*} p<.05 ;{ }^{* *} p<.01 ;{ }^{* * *} p<.001$

Neither capability measured by GPA from high school nor effort measured by working hours on average per week out of class do significantly affect the perceived self-efficacy level in economics.

Model 1 (a) shows that the independent variables explain $9 \%$ of the variation on the dependent variable on self-efficacy level. The $F$-value of the model is 7.72 ( $<.001)$. The computed variance inflation factor $(V I F)$ for the independent variables this model is an indicator of multicollinearity. All VIF values are below 1.091 and, hence, multicollinearity is no threat to the results of the ordinary least squares regression (Studenmund, 2006).

\subsection{Model 1 (b) Self-efficacy Level, Gender Interaction Included}

When gender is replaced by gender - temperament interaction the regression model reveals that not all female students are significantly related to perceived self-efficacy level. The female $S P$ students do not. However, the female $N F(\beta=$ $-.11, \mathrm{p}<.05)$ and $N T$ students $(\beta=-.11, \mathrm{p}<.05)$ affect self-efficacy level according to the overall gender effect.

Furthermore, only the male $N T$ students have a significant higher self-efficacy level $(\beta=.14, \mathrm{p}<.01)$ within the male group. Neither male $N F$ nor $S P$ students have significant higher self-efficacy level. The general conclusion that all male students have significantly higher self-efficacy level does not hold when temperaments are taken into account.

Model 1 (b) shows that the independent variables explain 5\% of the variation on the dependent variable on self-efficacy level. The F-value of the model is 3.62 ( $<$ <.001). The computed VIF values are below 1.053.

\subsection{Model 2 (a) Self-efficacy Strength, Gender Interaction Excluded}

Self-efficacy strength is the dependent variable and otherwise has the model identical independent variables as Model 1 (a). Gender does significantly affect self-efficacy strength. Male students have significantly higher self-efficacy strength than their female peers $(\beta=.24, \mathrm{p}<.001)$. The personality temperaments $N F, N T$, and $S P$ in this model include both female and male students. Hence, gender heterogeneity within each temperament group may dilute the effect on self-efficacy strength since none of them significantly affect self-efficacy strength. 
Self-efficacy strength is positively affected by student capability $(\beta=.10, \mathrm{p}<.01)$ and effort $(\beta=.19, \mathrm{p}<.001)$. The positive relation between strength and the independent variables capability and effort is expected.

No VIF value exceeds 1.062. The model fit measured by $F$-value is $14.74(\mathrm{p}<.001)$. The independent variables explain $9 \%$ of the variation in self-efficacy strength.

\subsection{Model 2 (b) Self-efficacy Strength, Gender Interaction Included}

Gender is replaced by gender - temperament interaction in this regression model. The result reveals that not all female students are significantly and negatively related to perceived self-efficacy strength. The model shows that female $N F$ students have no significant relation to self-efficacy strength. The female $N T(\beta=-.07, \mathrm{p}<.05)$ and $S P$ students $(\beta=$ $-.09, \mathrm{p}<.01)$ affect self-efficacy strength according to the overall gender effect.

On the other hand only the male $N T$ students have significantly higher self-efficacy strength $(\beta=.10, \mathrm{p}<.01)$ within the male group. Neither male $N F$ nor $S P$ students have significantly higher self-efficacy strength. The general conclusion that all male students have significant higher self-efficacy strength does not hold when temperaments are controlled for.

Model 2 (b) shows that the independent variables explain $6 \%$ of the variation in the dependent variable on self-efficacy strength. The $F$-value of the model is 7.21 (p < .001). All computed VIF values are below 1.032.

\section{Discussion}

The purpose of this study was to explore how gender and temperament type interactions affect student self-efficacy. The conclusion according to regression results is that gender does matter for the degree of self-efficacy level and strength in the subject studied. However, when gender-temperament interactions are included in the model, a new picture develops. The simple and direct relation between gender and self-efficacy level in Model1 (a) and strength in Model 2 (a) are replaced by more subtle, interactive effects on self-efficacy in Models 1 (b) and 2 (b).

Female and male students are heterogeneous groups when we look at the composition of temperaments. Table 2 reveals that there are a significantly higher part of $S J$ and $N F$ temperaments in the group of female students than among their male peers. On the other hand there are a significantly higher part of $S P$ and $N T$ temperaments in the male group compared to their female peers. These differences in the composition of personality temperaments may affect the gender - self-efficacy relation.

The results from Table 3 on self-efficacy disclose three major findings. First, we do not find that personality temperament affects self-efficacy when gender is controlled for. The strong and direct gender effect where female students have significantly lower self-efficacy than their male peers in Principles of Economics (Model 1a and 2a) has probably diluted some effect of temperament types. We have reached this conclusion since the other models reveal gender-temperament interaction effects when gender is replaced by interaction (Model $1 \mathrm{~b}$ and $2 \mathrm{~b}$ ).

Second, the strong gender effect on self-efficacy does not include all female temperaments. There is no significant impact on female students' self-efficacy level having $S P$ temperament. Neither do female $N F$ students significantly affect self-efficacy strength. Hence, the general conclusion of lower perceived self-efficacy level among female students does only include those having $N F$ and $N T$ temperaments. Self-efficacy strength is only affected by females having $N T$ and $S P$ temperament.

Third, the general result suggesting that all male students have higher self-efficacy in economics than female students has to be differentiated too. When gender is replaced by male-temperament interaction, there is no difference in self-efficacy score (both level and strength) for male $N F$ and $S P$ temperaments. Only male students having $N T$ temperament are significantly related to self-efficacy.

Another lesson from the present study is that appraisal of self-efficacy is an inferential process in which the relative contribution of capability and effort on self-efficacy must be considered. Perceived self-efficacy has turned out to be a significant determinant of performance that operates partially independent of underlying skills and capability in other studies (e.g. Locke et al., 1984; Schunk, 1984a, 1984b). There is no significant relation between capability and self-efficacy level in the present study. This result may be interpreted as support that self-efficacy operates independent of capability. However, this is not the case for self-efficacy strength, which is significantly affected by capability. There is a positive relation between capability and self-efficacy, but only strength is significantly affected.

High self-efficacy is associated with student coping effort. However, only self-efficacy strength is positively affected by effort in the present study. This result is in accordance with the theory of social learning where people with high degree of self-efficacy persist longer in coping efforts than people with low self-efficacy. This is not the case for self-efficacy level. This study reveals no significant relation between the perceived difficulty level of economics and 
student effort. An explanation may be that a greater part of female students worry more about difficulty and own coping ability than their male peers.

According to the theory of self-efficacy the extent to which students will alter their perceived efficacy through performance experiences will depend upon, among other factors, the difficulty of the task, the amount of effort they expend, the amount of teacher aid they receive, and the teaching styles and learning modes under which they perform. A study of teacher-centred versus student-centred teaching styles and learning modes in an introductory university statistics course revealed that the teacher-centred class was significantly higher rated on achievements in a quantitative classroom (Giles et al., 2006). Statistics and economics are closely related and, hence, understanding of the effect of teaching style in a quantitative classroom should have much in common. Their study concludes by demonstrating significant effects of teaching style and interactions with characteristics of individual student. However, self-efficacy and personality temperaments were no part of their study and they found no gender differences in achievement. The present study proposes to substitute gender with gender-temperament interactions in research on teaching style and learning modes in the future.

Another lesson from the present study is that these tools of improving self-efficacy have to be used differently when student gender-personality interaction are taken into account. Further research on the best ways of improving student self-efficacy, and thereby academic achievement, among the different gender-temperament types is requested.

\section{Contributions and Limitations}

As far as we know this is the first study to explore the relation of gender self-efficacy in an interaction with personality temperaments. The main contributions of this study are showing the need to go beyond gender to get a more complete picture of the differences in self-efficacy between female and male students. The personality temperaments among female and male students reveal heterogeneous gender groups, which ask for caution when conclusions about gender self-efficacy are drawn in the quantitative classroom.

The sample size includes more students than most studies of self-efficacy and especially studies exploring personality temperaments. The models explain slightly below $10 \%$ of the variation on self-efficacy level and strength but are significantly affected by some female and male personality temperaments. However, these significant gender-personality interactions still leave much variance of self-efficacy to other factors.

The voluntary participation in the study could probably cause some bias on the distribution of personality types in the present study. Students with personality types suited for the study of economics are more likely to participate. This bias may cause the importance of temperament effects on academic performance and self-efficacy to be underestimated slightly, since $S J$ students are probably more willing to participate than the other temperaments. Fallan (2006) found that business students are more likely to have a sensing and judging $(S J)$ personality temperament rather than a sensing and perceiving $(S P)$ and an intuitive and feeling $(N F)$. The second largest group of students at TBS were those being intuitive and thinking $(N T)$. However, this is hardly any serious threat to the present study because most students participated.

A principal limitation of the current study is that it is carried out in the setting of economics and the quantitative classroom. Future research should explore how gender and temperament type interactions affect self-efficacy in other subjects.

\section{References}

Anderson, B., Benjamin, H., \& Fuss, M.A. (1994). The determinants of success in university introductory economics courses. Journal of Economic Education, 25, 99-119. http://dx.doi.org/10.2307/1183277

Bandura, A. (1986). Social Foundations of Thought and Action. Englewood Cliffs, NJ: Prentice-Hall.

Bandura, A. (1997). Self-efficacy: The exercise of control. New York: Freeman.

Bandura, A. (2012). On the Functional Properties of Perceived Self-Efficac. y Revisited. Journal of Management, 38(1), 9-44. http://dx.doi.org/10.1177/0149206311410606

Barrick, M.R. \& Mount, M.K. (1991). The Big Five Personality Dimensions and Job Performance: A Meta-Analysis, Personnel Psychology, 44(1), 1 - 26. http://dx.doi.org/10.1111/j.1744-6570.1991.tb00688.x

Benfari R. \& Knox J. (1991). Understanding Your Management Style. Beyond the Myers-Briggs Type Indicators. (Lexington Books).

Borg, M.O., Mason, P.M. \& Shapiro, S.L. (1989). The Case of Effort Variables in Student Performance. Journal of Economic Education, 20, 308-313 http://dx.doi.org/10.1080/00220485.1989.10844634 
Borg, M.O. \& Shapiro, S.L. (1996). Personality Type and Student Performance in Principles of Economics. Journal of Economic Education, 27, 3-25. http://dx.doi.org/10.1080/00220485.1996.10844890

Borg, M.O. \& Stranahan, H. (2002a). The effect of gender and race on student performance in principles of economics: the importance of personality type. Applied Economics, 34, 589-598. http://dx.doi.org/10.1080/00036840110039249

Borg, M.O. \& Stranahan, H. (2002b). Personality Type and Student Performance in Upper-Level Economics Courses: The Importance of Race and Gender. Journal of Economic Education, 33 (Winter), 3-14. http://dx.doi.org/10.1080/00220480209596120

Buckles, S.G., \& Freeman, V. (1983). Male-female differences in the stock and flow of economic knowledge. Review of Economics and Statistics, 65, 355-358. http://dx.doi.org/10.2307/1924506

Durden, G. \& Ellis, L. (1995). The Effects of Attendance on Student Learning in Principles of Economics. American Economic Review, 85, 343-346.

Fallan, L. (2006). Quality Reform: Personality Type, Preferred Learning Style, and Majors in a Business School. Quality in Higher Education, 12(2), 193-206. http://dx.doi.org/10.1080/13538320600916817

Fallan, L. \& Opstad, L. (2003). Student Performance in Principles of Macroeconomics: The Influence of Gender, Ability, Effort, and Self-Efficacy (In Norwegian only). In Frihet og mangfold, Fallan, L. \& Gustafson, O. (Eds.) Trondheim Business School.

Fallan, L. \& Opstad, L. (2014). Beyond gender performance in accounting: Does personality distinction matter? Accounting Education: an international journal, 23(4), 343-361. http://dx.doi.org/10.1080/09639284.2014.930693

Ferber, M.A., Birnbaum, B.G., \& Green, C.A. (1983). Gender differences in economic knowledge: A re-evaluation of the evidence. Journal of Economic Education, 14, 24-37. http://dx.doi.org/10.1080/00220485.1983.10845013

Galyon, C.E,, Blondin, C.A., Yaw, J.S., Nalls, M.L., \& Williams, R.L. (2012). The relationship of academic self-efficacy to class participation and exam performance. Social Psychology of Education, 15, 233-249. http://dx.doi.org/10.1007/s11218-011-9175-x

Gegenfurtner, A., Veermans, K., \& Vauras, M. (2013). Effects of computer support, collaboration, and time lag on performance self-efficacy and transfer of training: A longitudinal meta-analysis. Educational Research Review, 8 , 75-89. http://dx.doi.org/10.1016/j.edurev.2012.04.001

Giles, J., Ryan, D.A., Belliveau, G., de Freitas, E. \& Casey, R. (2006). Teaching style and learning in a quantitative classroom. Active learning in higher education, 7(3), 213-225. http://dx.doi.org/10.1177/1469787406069055

Gist, M.E. (1987). Self-efficacy: implications for organizational behaviour and human resource management. Academy of Management Review No. 3.

Gist, M.E. \& Mitchell, T.R. (1992). Self-efficacy: a theoretical analysis of its determinants and malleability. Academy of Management Review, (2), 182-211. http://dx.doi.org/10.5465/amr.1987.4306562

Gohmann, S. \& Spector, L.C. (1989). Test scrambling and student performance. Journal of Economic Education, 20, 235-238. http://dx.doi.org/10.1080/00220485.1989.10844625

Judge, T.A., Jackson, C.L., Shaw, J.C., Scott, B.A., \& Rich, B.L. (2007). Self-efficacy and work-related performance: The integral role of individual differences. Journal of Applied Psychology, 92, 107-127. http://dx.doi.org/10.1037/0021-9010.92.1.107

Keirsey, D. \& Bates, M (1984). Please understand me: Character and temperament types. $5^{\text {th }}$ ed. Del Mar: California: Prometheus Nemesis.

Kelley, A.C. (1975). The student as an utility maximizer. Journal of Economic Education, 6, 82-92. http://dx.doi.org/10.2307/1182457

Lawrence G.D. (1993). People types and tiger stripes: A practical guide to learning styles. 3rd ed. Gainsville, Fla.: Center for Application of Personality Types.

Lent, R.W., Brown, S.D., \& Gore, P.A. (1997). Discriminant and predictive validity of academic self-concept, academic self-efficacy, and mathematics-specific self-efficacy. Journal of Counseling Psychology, 44, 307-315. http://dx.doi.org/10.1037/0022-0167.44.3.307 
Leppel, K. (1984). The Academic Performance of Returning and Continuing College Students: An Economic Analysis. Journal of Economic Education, 15, 46-54. http://dx.doi.org/10.2307/1182501

Locke, E.A., Zubritzky, E., Cousins, E., \& Bobko, P. (1984). Effect of previously assigned goals on self-set goals and performance. Journal of Applied Psychology, 69, 694-699. http://dx.doi.org/10.1037/0021-9010.69.4.694

Lumsden, K.G. \& Scott, A. (1987). The economics student re-examined: male-female differences in comprehension. Journal of Economic Education, 18, 365-37. http://dx.doi.org/10.1080/00220485.1987.10845228

Marburger, D.R. (2001). Absenteeism and Undergraduate Economic Performance. Journal of Economic Education, 32, 99-109. http://dx.doi.org/10.1080/00220480109595176

Opstad, L. \& Fallan, L. (2010). Student Performance in Principles of Economics: The Importance of Gender and Personality. International Review of Economics Education, 9(1), 76-92. http://dx.doi.org/10.1016/s1477-3880(15)30059-1

Owen, S.V. (1986). Using self-efficacy in program evaluation. Paper presented at the annual meeting of the American Educational Research Association, San Francisco, CA, April 1986, 16-20

Park, K.H. \& Kerr, P.M. (1990). Determinants of Academic Performance. Journal of Economic Education, 21, 101-111. http://dx.doi.org/10.1080/00220485.1990.10844659

Parker, K. (2006). The effect of student characteristics on achievement in introductory microeconomics in South $\begin{array}{lllll}\text { Africa. South African Journal of } & \text { Economics, } & \text { 74(1), }\end{array}$ http://dx.doi.org/10.1111/j.1813-6982.2006.00054.x

Peters, M.L. (2012). Examining the relationship among classroom climate, self-efficacy, and achievement in undergraduate mathematics: A multi-level analysis. International Journal of Science and Mathematics Education, 11, 459-480. http://dx.doi.org/10.1007/s10763-012-9347-y

Rhine, S.L. (1989). The effect of state mandates on student performance. American Economic Review, 79, 231-235.

Romer, D. (1993). Do students go to class? Should they? Journal of Economic Perspectives, 7, 167-174. http://dx.doi.org/10.1257/jep.7.3.167

Schmidt, R.M. (1983). Who Maximizes What? A Study in Student Time Allocation. American Economic Review, 73(2), 23-28.

Schunk, D.H. (1984a). Enhancing self-efficacy and achievement through rewards and goals. Motivational and informational effects. Journal of Educational Research, 78, 29-34. http://dx.doi.org/10.1080/00220671.1984.10885568

Schunk, D.H. (1984b). Self-efficacy perspective on achievement behaviour. Educational Psychologist, 19, 48-58. http://dx.doi.org/10.1080/00461528409529281

Siegfried, J.J. (1979). Male-female differences in economic education: a survey. Journal of Economic Education, 10, 1-11. http://dx.doi.org/10.1080/00220485.1979.10845477

Stratford, D. \& Sulock, J. (1995). Estimating Production Functions with Correction for Drops. Journal of Economic Education, 25, 101-112. http://dx.doi.org/10.1080/00220485.1995.10844862

Studenmund, A.H. (2006). Using Econometrics: A Practical Guide. $5^{\text {th }}$ edn, Upper Saddle River, NJ: Prentice-Hall.

Stajkovic, A.D. \& Luthans, F. (1998). Self-Efficacy and Work-Related Performance: A Meta-Ananlysis. Psychological Bulletin, 124(2), 240-261. http://dx.doi.org/10.1037/0033-2909.124.2.240

Swope, K.J. \& Schmitt, P.M. (2006). The performance of economics graduates over the entire Curriculum: the determinants of success. Journal of Economic Education, 37, 387-394. http://dx.doi.org/10.3200/jece.37.4.387-394

Usher, E.K. \& Pajares, F. (2008). Sources of Self-Efficacy in School: Critical Review of Literature and Future Directions. Review of Educational Research, 78(4), 751-796. http://dx.doi.org/10.3102/0034654308321456

Vancouver, J.B. \& Kendall, L.N. (2006). When self-efficacy negatively relates to motivation and performance in a learning context. Journal of Applied Psychology, 91, 1146-1153. http://dx.doi.org/10.1037/0021-9010.91.5.1146

Watts, M. (1987). Student gender and school district differences affecting the stock and flow of economic knowledge. Review of Economics and Statistics, 69, 561-566. http://dx.doi.org/10.2307/1925550 
Williams, M.L., Waldauer, C., \& Duggal, V.G. (1992). Gender Differences in Economic Knowledge: An Extension of the Analysis. Journal of Economic Education, 23(3), http://dx.doi.org/10.1080/00220485.1992.10844756

Yeo, G.B. \& Neal, A. (2006). An examination of dynamic relationship between self-efficacy and performance across levels of specificity. Journal of Applied Psychology, 91, 1088-1101. http://dx.doi.org/10.1037/0021-9010.91.5.1088

Ziegert, A.J. (2000). The role of personality temperament and student learning in principles of economics: Further evidence. Journal of Economic Education, 31(4), 307-322. http://dx.doi.org/10.1080/00220480009596449

Zimmerman, B.J. (2000). Self-Efficacy: An Essential Motive to Learn. Contemporary Educational Psychology, 25, 82-91. http://dx.doi.org/10.1006/ceps.1999.1016 